\title{
Pretty Little Liars: Teen Mystery or Revealing Drama?
}

\author{
PATRICK BINGHAM, University of East Anglia
}

\begin{abstract}
Teen television scholarship foregrounds debates surrounding representation, maturation anxieties, and the inclusion of all types of programmes geared towards teenaged viewers into one overarching genre: Teen Television (Davis and Dickinson 2004; Ross and Stein 2008). However, little work has been done on the prevailing sub-genres within this classification. This exclusion runs parallel to the minute amount of scholarship available on mystery television, a genre identified by Ira O. Glick and Sidney J. Levy in 1962, yet remains seemingly unmentioned, or forgotten rather, in contemporary television genre studies. Consequently, the exclusion of mystery, much like the focus on redefining a corpus of programmes into a new, broader genre Teen TV, undermines the potential of those forgotten genres to negotiate socio-cultural issues. In this case study, I identify mystery programming as one of those genres elided by another. Thus, my argument is that through undermining the importance (here, cultural relevance) of one genre over another, a system of genre hierarchisation emerges that is closely related to the ability (or lack thereof) to address sociocultural issues. In other words, if a particular social issue, such as teen (homo)sexuality, is not present in this genre but in other lesser genres, then there is limited attention paid to those genres that are actually engaging with important socio-cultural concerns. To illustrate this, I explore Pretty Little Liars (ABC, 2010- ) as a teen television programme because of its narrative arc surrounding teen homosexuality and how it uses mystery to explore, develop and negotiate this contemporary cultural issue.
\end{abstract}

\section{KEYWORDS}

Teen television, Pretty Little Liars, sexuality, queer theory, television genres, mystery, drama.

\section{Introduction}

Much of the work on teen television focuses variously on the gendering of programming; high'quality' drama; establishing 'teen television' as a homogenous genre; issues of representation; and the plethora of anxieties associated with teen identity and maturation (see Davis and Dickinson 2004 and Ross and Stein 2008). Therefore, in this article, I explore the ways in which academics, critics and the industry seemingly align 'drama' as the ostensible negotiator of these socio-cultural (teen) issues. This then elides other generic categories, as 'drama' is seen to employ a higher level of cultural power in television programming. I will specifically engage with mystery as one of those generic categories elided, as it is overlooked or, rather, underestimated in terms of its ability to imbue a sense of cultural relevance and/or political significance. Of course, I do not lay the claim that the loosely defined generic category 'drama', as opposed to the dramatic form, ${ }^{1}$ is the sole

\footnotetext{
${ }^{1}$ Bruce Carson and Margaret Llewellyn-Jones define 'dramatic form' as 'the cliffhanger endings, multiple characters and storylines' which 'have influenced drama series across a range of genres' $(2000,7)$.
} 
socio-cultural negotiator. Similarly in The Sitcom (2009), Brett Mills argues for the merits of the sitcom, which have also been often overlooked. In order to continue Mills' complication of the privilege afforded 'drama', here I will take the teen-oriented television series Pretty Little Liars (ABC Family, 2010- ) due to its current popularity, ${ }^{2}$ its high-profile acclaim as 'ABC Family's latest drama' (Ernst 2010), its apparent generic hybridity, and the show's purported attempts to negotiate contemporary teen issues. One of those issues is developed through a major story arc that deals with teen (homo)sexuality - a controversial, contemporary issue for American, and arguably Western, teen programming (see Dhaenens 2012; Callister et al. 2012; and Meyer and Wood 2013). Pretty Little Liars operates on the border between mystery and drama, thus indicating a line that its critics and marketers are unwilling to cross in labelling the series a teen mystery, demonstrating the cultural capital that the label 'drama' carries. By undermining the importance (that is, cultural relevance) of one genre for another, it produces a system that hierarchises genre and thus sociocultural issues. In other words, if a particular social issue, such as teen (homo)sexuality, is not present in this genre but in other lesser genres, then there is limited attention paid to genres that are actually engaging with those important contemporary concerns.

In the first section of this article, I explore 'drama' and mystery as possible generic categories and their places within an assumed television genre hierarchy. I then investigate the ways in which the show's narrative navigates this generic blending, emphasising how the overwhelming elements of mystery affect the drama, rather than vice versa. This provides an instance for the interrogation of these genres and how they work to represent teen homosexuality within and outside popular television programming. I focus on Emily Fields's (Shay Mitchell) overarching narrative surrounding her coming out. Much of the drama related to this story arc is exaggerated by the encroaching mystery revolving around the death of her best friend Allison DiLaurentis (Sasha Pieterse) and how Allison was the initial object of Emily's lesbian desire.

In the second section of the essay, however, I explore the reception of Pretty Little Liars and show how that reception centralises 'drama' as the key generic component of the series, rather than mystery. The types of reception I primarily focus on are critical reviews, but I also engage with the series' webpage on ABCFamily.com and press releases associated with the television show. These examples highlight and epitomise the ways in which the industry and the critics understand and categorise television series into genres; but, more importantly, they further demonstrate the exclusion of mystery, both within academia and the industry, as a legitimate genre with the ability to confront or negotiate relevant cultural issues.

\section{What Defines 'Drama'?}

Alison DiLaurentis (Sasha Pieterse) has been missing for over a year when the four principal characters reunite in Pretty Little Liars. Aria Montgomery (Lucy Hale), Spencer Hastings (Troian Bellisario), Hanna Marin (Ashley Benson) and Emily Fields (Shay Mitchell) all share one thing: they were best friends with Alison. Their group dynamic (the 'it' girls, the beauties, and more often than not, minions of the terrific Allison) rekindles as each girl receives mysterious texts, letters and

\footnotetext{
${ }^{2}$ Bill Keveney (2013) writes that 'ABC Family's Pretty Little Liars comes back for its fourth-season premiere Tuesday (8 p.m. ET/PT) as a social-media phenomenon that's struck a chord with its young audience.' In much of the critical reception surrounding the show, it is often labelled as a 'social-media phenomenon' which signifies success in today's television market.
} 
e-mails from 'A', the assumed nom de plume of their dead friend. A's communication is one sided and increasingly hostile, referring to the girls as 'bitches' or 'whores,' and assuring each one that their lies and secrets will be revealed. Mystery is arguably the central structuring device of the overarching narrative, working to craft an unending game of cat-and-mouse concerning the truth behind Alison's disappearance. The theme song and corresponding visuals further emphasise the overwhelming state of mystery apparent in the show, as we hear "Two can keep a secret / If one of them is dead" while the four main characters appear standing over a coffin as Aria puts a finger over her mouth as if to shush the audience.

In order to explore the generic categories of 'drama' and how this generic label is consistently applied to contemporary television programming, I utilise the applied definition of 'drama' put forward by Bernadette Casey et al. in Television Studies: The Key Concepts (2012). I have chosen this definition because it works to define historically and contemporaneously the 'drama' genre in terms of cultural significance, as well as in terms of generic specificity. In other words, the scholars approach the definition of 'drama' critically (looking at its role to navigate the murky waters of cultural criticism). Their definition for contemporary television programming in the US and the UK claims that drama

comes in many formats [...]. Moreover, television drama now commonly embraces overlapping multi-narratives, postmodern self-consciousness [...]. In short, while much television drama continues to rely on certain familiar settings, including the crime/police series (original emphasis), hospital dramas and community-based narratives they also display innovation in narrative and technique. [...] TV drama has become characterised by high degrees of generic instability. (Casey et al. 2012, 89-90)

Significant in this definition is that it juxtaposes generic purity with cultural implications ('postmodern self-consciousness'), especially as it pertains to the stereotypical or archetypal 'drama' series. Furthermore, inherent in this definition and the television shows associated with 'drama' is a level of cultural authority, meaning that they (both the genre and its shows) are arguably situated as 'highbrow entertainment' in the invisible generic hierarchy of television programming. This definition suggests that, if one were to align the genres in terms of 'quality', 'drama' would rank higher on the scale of prestige and 'seriousness' than say 'comedy' or 'mystery'. However, what is not apparent in this definition is the distinction between 'drama' and the 'dramatic form' (Carson and Llewellyn-Jones 2000, 7). For the purposes of this article, I am drawing a distinction between 'drama' as a serious, straight-minded programme that often intermixes with other genres and is seen as high culture programming, (see, for example, Downton Abbey (2010- ), The West Wing (1999-2006), Mad Men (2007- ). ${ }^{3}$ Moreover, 'drama' in this sense would shirk a melodramatic mode (see Mittell 2012-13), even though there may be remnants of this throughout all genres.

Mystery, then, if it embraces the melodramatic mode, should be said to embrace low culture (or less serious-minded and even undereducated viewers) and employ a low quality aesthetic. Concordantly, mystery seemingly falls to the wayside in academic scholarship surrounding the study of television genres. While Sharon Marie Ross and Louisa Ellen Stein's edited collection Teen Television (2008) provides some academic work on Veronica Mars (CBS, 2004-2007), it does not account for the show's generic label 'mystery' being explicitly named as a possible category.

\footnotetext{
${ }^{3}$ While these programmes may seem to operate within entirely different genres, they contain an underlying "seriousness" or "highbrow" aesthetic in their narratives and characterisations. This lies within the same debate surrounding 'quality' TV (see McCabe and Akass 2007) and 'complexity' of narrative (see Mittell 2012-13).
} 
Furthermore, Ross and Stein's main contribution to genre studies is working to include teen shows as a generic category on its own. Additionally, The Television Genre Book (Creeber et al. 2008) and Television Studies: The Key Concepts (Casey et al. 2012) leave out mystery altogether. These books locate the 'police' or 'crime' shows within the realm of 'drama', suggesting overtly the cultural relevance 'drama' has obtained through its cultural hold over mystery itself. Contrary to the exclusion of mystery within television scholarship, mystery has remained an important classification within popular literature and film, as suggested by John Cawelti in Mystery, Violence, and Popular Culture (2004).

Based upon these academic exclusions, 'mystery' is therefore easily read as subordinate within a generic hierarchy, suggesting that it does not provide the same cultural relevance as 'drama'. Of course, popular discourses, which will be discussed later in this article, formulate other approaches to genre classification; specifically, one that does not ignore mystery as a possible generic category. Ira O. Glick and Sidney J. Levy provide the most succinct definition in their book Living With Television (1962). Glick and Levy identify the rudimentary aspects of the 'suspense-mystery' programme, highlighting how it innately involves 'higher levels of excitement, curiosity, and intellectual challenge' $(1962,122)$. Moreover 'suspense may be the predominant factor, appealing to the arousal of emotions of foreboding and anticipation,' but also that 'the puzzle predominates' suggesting that 'at the heart of all suspense and mystery programs is the quest for revelation' (Glick and Levy 1962, 123). As much of the contemporary literature on mystery television is lumped under 'detective' or 'police-drama', this further perpetuates the recent invisibility of mystery as a genre. They focus more on the actions of mystery solving within the programmes themselves, rather than on the isolation of the elements of mystery in terms of generic conventions and narrative. Thus, this inability of present scholarship to recognise the narrative and the generic elements reduces or conceals any possibility of the genre's ability to become a force of cultural power and socio-culture issue solvent. More importantly, nonetheless, is that the scholarship on television genres systematically avoids defining or labelling mystery as a distinctive genre, when mystery remains an important part of television broadcasting and an important genre in literature and the theatre. While admittedly mystery does generally revolve around 'sleuthing' or detective stories, it also works as a narrative device to provide suspense and awe; and, additionally, to serialise the narrative.

\section{Queer(ing) Mystery}

Mystery is neither a queer nor heterosexual genre per se, rather one may see the links between queer and mystery because of those specific generic conventions that revolve around surfacing buried secrets, villains and heroes staying on the periphery of the public sphere (typically in the shadows), using alternative identities (as with 'A' in the case of Pretty Little Liars). Stephen Farrier argues that 'Queerness is a lot like soap opera. It can be fun, rambunctious, hilarious, touching, exciting and can sometimes be downright irritating and annoying' (2000,86). Farrier touches on some of the conventions and interpretations of or reactions to soap opera, on which one may easily draw when discussing mystery. Further, as soap opera and mystery may function as melodrama more so than as 'quality' dramas - exemplified in popular discourses (i.e., television reviews in both the mainstream presses and on popular movie and television forums, such as IMDB.com) - it highlights why, other than the minimal work on mystery television programming done in the $1960 \mathrm{~s}$ (Glick and Levy 1962), little attention has been paid to the mystery genre in spite of the recent prevalence within prime time programming (see Lost (2004-2010), Veronica Mars (2004-2007), 
Desperate Housewives (2004-2012), Pretty Little Liars (2010- )). ${ }^{4}$ And thus, the attention of scholars in recent years has focused predominately on those 'quality' TV programmes.

Arguably, then, this exclusion of a popular (historic) genre may be seen to evoke similar exclusion of the queer storyline or queer figures within popular television series and films. Only recently, within the past twenty years, have we seen a proliferation of gay, lesbian and bisexual characters in popular televisual media (see Gamson 2005; Becker 2006; and Davis and Needham 2009). 'Drama' would be seen by critics, the industry and academics alike, therefore, as the ostensible genre to accomplish the appropriate negotiation, commentary and intervention. Admittedly, there are many such teen and adult 'drama' programmes that provide coming out narratives and address the issue (see The O.C. (2003-2007), Dawson's Creek(1998-2003), Greek (2007-2011), and Skins (20072013)). Similarly, in Pretty Little Liars, as Emily's coming out narrative develops, the audience soon learns that Emily's personal life will be a primary source of the show's mystery.

Dennis Allen's article 'Homosexuality and Narrative' (1995) discusses how the homosexual narrative within Melrose Place (1993-1999) dominates the heterosexual narrative, arguing that, 'in the heterosexual imaginary that dominates the show, the revelation of homosexuality is the only story that can be told about it' $(1995,610)$. Likewise, the 'homosexual narrative' within Pretty Little Liars is situated within the overarching mystery narrative, and is therefore the 'only story that can be told about it' $(1995,610)$. Emily is constantly reminded through texts and handwritten letters her love for the deceased Allison. As she slowly comes to terms with her own identity, 'A' disrupts that space for contemplation and self-awareness, forcing her to either come out herself or be 'outed' by the conniving ' $A$ '. The stalker/victim model utilised for the initial part of the series hyperbolises Emily's situation with the death of her best friend and wanted lover. Yet, it also hyperbolises mystery elements in the narrative itself. For instance, in Greek, Calvin Owens (Paul James) withholds his sexual orientation, creating a space for 'drama' to negotiate his situation within the ostensibly homophobic American university fraternity and sorority system. As he does open up to his future fraternity brothers about his sexuality, the melodramatic conflict is solved and 'drama' has intervened in a world of rampant ignorance, due to their (eventual) acceptance of him. By contrast, with Emily, the viewer has no concrete evidence that she is gay, until the show uses textual features to allude to her sexual preference. For instance, in the pilot episode, Emily meets Maya (her future partner), a girl that has recently filled Allison's vacancy, both within the physical realms of the latter's home, but also within Emily's affections. Whenever Maya and Emily are seen together, they are almost always portrayed in pastel costuming or pastel lighting. Opposite to this is the darkness that surrounds her interactions with Ben, her short-lived heterosexual romance. In one such scene, he lets out his sexual frustrations on Emily, thrusting her against cold steel lockers in the female locker room, making attempts at moving beyond platonic coupling towards a more open, sexualised partnership. The scared, fractured looks on Emily's face as she cries out for help mirror the darkness on the boarder of the locker room, which also echo the overall dark appearances of Ben (he is dressed in a navy blue track suit, has jet black hair, very tanned, and is positioned in an opposing or threatening manner).

The mystery validates both the audience's assumption and textual foreshadowing, when her latent attraction to women is made explicit through an aggressive text message from 'A'. 'Precisely

\footnotetext{
${ }^{4}$ Categorised as such through Internet Movie Database's (IMDB) 'Most Popular Mystery TV Series' (see Anon. 2014a).

${ }^{5}$ See Pilot episode for Pretty Little Liars (2010).
} 
because homosexuality is not assumed but is itself the secret that produces narrative complication,' argues Dennis Allen, 'the disclosure of homosexuality is continually substituted for any possible narrative, romantic or otherwise, predicated on such a sexuality' $(1995,611)$. Mystery works to disrupt or fracture the assumed narrative (Emily's assumed heterosexuality), creating a new, aggressive narrative. In this new narrative, ' $\mathrm{A}$ ' is the powerful person (mysterious, omnipotent and seemingly omnipresent), disrupting Emily's control by not allowing Emily to withhold her sexual orientation. The show, therefore, works in opposition to Allen's claim that the narrative will hold back and do anything to avoid the 'homosexual narrative.'

Notwithstanding, the preclusion of mystery within television scholarship and the proclivity for 'drama' as the generic label invested with cultural capital, mystery in Pretty Little Liars is clearly working to negotiate (teen) sexuality. In other words, mystery has the ability to represent or portray teen homosexuality and present the socio-cultural implications surrounding this present issue. Moreover, the show presents it not within a negative light, so therefore, the conscious decisions made in editing, scripting and acting provide a particular, positive commentary. Without 'A', Emily's coming out narrative would be mundane and cliché, limiting the scope of the show's ability to demonstrate the complexity of (female) teenage life. Mystery incises typical, ordinary American lives, akin to the way 'drama' intervened in Capeside, the fictional town in Dawson's Creek (19982003) as Jack McPhee (Kerr Smith) disrupted the heterosexual narrative by coming out. If mystery operates diachronically to 'drama', then why does mystery not stand out (a) as a genre of its own accord and (b) as a potential cultural negotiator? Ira O. Glick and Sidney J. Levy mention in their definition of 'suspense and mystery' that '[these] shows are provocative and sometimes controversial because they often combine violence and eroticism or hint at sophisticated or perverse relationships' $(1962,124)$. Whilst I am firmly against the notion that Emily's identity and her relationships fall under the category of 'perverse,' her identity and her relationships are sophisticated. She must overcome her own personal anxieties about homosexuality, her culture's anxieties about teenage relationships more generally whilst simultaneously assisting her friends in discovering the secret identity of 'A', which will also reveal Allison's killer.

Glyn Davis and Kay Dickinson address the same issue of the role of teen-related subject matter in defining genre in regards to 'teen TV': 'is there a teen genre per se, or is what we call teen TV simply a collection of different, previously existing genres, mutated in order to take adolescent sensibilities into account' (Davis and Dickinson 2004, 6)? While this does not explicitly address why mystery is unable to stand alone as a genre in current television scholarship, it does imply that, like 'teen TV,' it is often overlooked or unmentioned so the other culturally empowered genres may lay claim. Moreover, this relates explicitly to the way LGBT narratives are often elided by the heterosexual narrative. Joshua Gamson speaks to this problem of 'tele-visibility,' highlighting gay male visibility as originating in the talk-show, then moving into the reality TV sector as a means of 'mainstreaming' gay male identity (2005). In fictionalised TV programming, homosexual story arcs are historically used to disrupt or fracture the show's apparent 'reality', but are soon forgotten upon discovery of a heteronormative resolution (the character moving away; the character returning to live a 'normal', heterosexual life; the character maintaining normative gender roles, and so forth) (Allen 1995, 613). Conversely, in the realm of literature, mystery fiction since the 1990s has seen an increase in gendered 'detective' stories and 'increasing numbers of homosexual and lesbian investigators' (Cawelti 2004, 289). This is revealing in that, within literature, mystery has the cultural power to portray or address issues of sexuality and gender openly, whilst television programming has been relatively slow in exploring these issues openly (see Gamson 2005; Davis and Needham 2009; Dhaenens 2012; and Meyer and Wood 2013). 
As Emily becomes more entrenched in her sexuality, and with ' $A$ ' further invading the privacy of Emily's life, the show provides the audience the opportunity to be an emotional activist for Emily, vying for her safety and acceptance within the community and by her family. Frederik Dhaenens recognises this position of the 'outed' gay teen in his article 'Teenage queerness' (2013), identifying the stages of recognition, coming out and victimisation necessary for the narrative surrounding teen homosexuality. However, Dhaenens poses the position of these character types between heteronormativity and homonormativity - simply put, what is normal for heterosexuals and homosexuals within their separate respective worlds (307-308). The generic conventions of mystery work hard to convince the viewer that Emily's sexuality is legitimate and not unnatural, because, in spite of the vicious nature of the cryptic messages, ' $A$ ' does not refer to her as unnatural or non-normative. The series' narrative does not necessarily make her choose between heteronormativity and homonormativity, rather it allows her to self-identify however she chooses. Her sexual orientation acts merely as a catalyst for a series of events laid out for the viewers (and the protagonists) that continues the narrative in a unilateral direction: solving the mystery of Allison's death and discovering the identity of 'A'.

Ultimately, mystery is working to intervene directly in this contemporary cultural (teen) issue, in spite of the ways in which 'drama' has been seemingly deemed as the sole generic category capable of depicting, and thus providing commentary on, contemporary American teenage lives. Understanding the ways in which the industry, the critics and the fandom interpret the relevance 'drama' has over these significant issues does not delimit the relevance mystery has in also navigating or negotiating them. In spite of what the network has done to solidify 'drama' as the principal generic category for Pretty Little Liars, Emily's storyline, interwoven into the mystery narrative, illustrates how her sexuality acts as a catalyst for the development of that mystery. This is a clear indication that genre is fluid, but more importantly that, as Jason Mittell claims, '[by] grounding genre categories in cultural contexts, their links to power relations often emerge in unexpected ways' $(2004,27)$. Mystery does demonstrate the 'power relations' evident within the series, particularly as it negotiates (teen) sexuality. Just as Emily's sexuality 'emerges in unexpected ways,' so too does mystery itself as it works to relay the cultural capital previously prescribed to 'drama.'

\section{Why 'Drama is the Mystery' and why Critics Mysteriously Overuse It}

In Genre and Television, Mittell argues that genre is not a culturally displaced categorisation, but rather that genres are 'situated within larger systems of power' $(2004,27)$. Cultural discourse signifies these 'systems of power,' whereby one generic categorisation outweighs or carries more cultural significance than the other. $\mathrm{ABC}$ Family and reviewers position certain genres as more worthy, especially as key genres (like 'drama') are seen to represent, portray or address important socio-cultural issues. Pretty Little Liars is not immune to this process of generic labelling. Immediate rendering of the series as 'drama' provides the it with a heightened level of importance, an indication that the show will not only provide quality entertainment, but also engage with and comment on issues of teen sexuality, truancy, thievery, violence, and so on. Whichever way the show is marketed by its broadcast network or discussed in the critical media does not necessarily subject the show to a specific generic labelling, however. It merely predicates a preference for specific genre types (see Mittell 2001, 5-7); and those preferences are echoed in the critics' responses to the show. 
As part of a larger system of power, ABC Family, a subsidiary of the Disney/ABC Group, operates meticulously to render their organisation as one that speaks to the contemporary American family. The 'ABC Family Description' claims they feature

programming reflecting today's families, entertaining and connecting with adults through relevant stories about today's relationships, all told with diversity, passion, humor and heart. ABC Family's programming is a mix of network defining original series and original movies, quality acquired series and blockbuster theatricals. (Anon. 2012)

These qualities of programming illustrate an adherence to specific genres the network prefers: ones that can discursively intervene with or comment on contemporary familial issues. Moreover, these programming aims recall Jason Mittell's claim that 'a spectrum of generic conventions and assumptions [...] are explicitly tied to greater systems of cultural power and differentiation' (2004, 27). It is, therefore, the network's prerogative to conceptualise and capitalise on the young adult mystery book series Pretty Little Liars, by Sara Shepard, thus, reifying 'teen mystery' as 'teen drama'.

Pretty Little Liar's premiere press release from 6 May 2010, issued by ABC Family, outlines the narrative initially as a mystery, and then refocuses the intent of the show towards 'drama' as they attempt to interrogate the complicated lives of the four protagonists. Much of the language, in spite of its narrative revolving around mystery, situates the show as a 'drama', particularly in the descriptions of the four girls. For example:

Once-chubby Hanna has transformed herself into the current "It girl," but still battles the urge to binge. Shoplifting gives her a less fattening thrill, but when she gets caught, the charges are dismissed only because her mother [...] takes matters into her own hands, eager to keep her own reputation and the image of her daughter untarnished. (Anon. 2010)

'Once-chubby', 'transformed herself into', 'battles the urge to binge' centralise supposedly feminine and teen issues above the mystery, perpetuating the show's seriousness and ability through its representation to comment on the aforementioned issues (Anon. 2010). Conversely, these issues are expounded upon by the mystery. Hanna's untarnished reputation is threatened by the anonymous 'A's revelatory and demanding text messages, so bold they force her to commit further acts of mischief to maintain her secret habits and reputation in tact. If 'drama' were truly the central generic element of the show that works to comment on and intervene with contemporary teen issues, then why employ mystery to dramatise or hyperbolise those situations? Does it not intensify and refocus the mystery element to the forefront of the viewer's mind when unknown, mysterious texts forcefully enact a narrative disruption? Ultimately, mystery's lasting affects on the viewer and the narrative reconceptualises implied genre and actual genre. In other words, the implied genre (drama) is complicated and fractured allowing the actual genre (mystery) to affect that viewer and his/her conception of what the overarching narrative is.

This is not to say that drama cannot be intrinsically linked to the overarching narrative, nor is mystery the only important generic category of the television show. However, when one genre is situated higher on an implied hierarchy merely from its assumed cultural power to negotiate with, commentate on or intervene in (in this case, teen) issues, then the other genres blended within the show are often overlooked or underestimated. Such is the case with mystery in Troy Patterson's article on the show in Slate Magazine, which takes a different angle than ABC Family, which emphasises its tendency towards 'soap-opera'. His belittlement of 'soap-operas' and 'teen dramas' 
is apparent in that he focuses on the show's aesthetics (both in terms of the text and the actresses) to beleaguer fashion-centred, girly 'dramas', arguably the 'soap-opera' (or mysteries if you will). ${ }^{6}$ For instance, in his commentary he mockingly claims that Pretty Little Liars 'is totally soapy in two respects: The cast members activating its teen intrigues - a foaming lather of frippery - give every indication of having sashayed straight out of an ad for designer shampoo' (Patterson 2010). This description aggrandises the (lacking) cultural impetus associated with 'soap-operas' and connected teen genres (Patterson 2010). Of course, he also almost completely misses the presence of mystery within the show. While he does make passing mention of the mysterious happenings, mystery is completely elided as a genre. Rather, he emblazons 'soap-opera' over 'drama' as a means to mock or belittle any seriousness of a character's cheating father and the matters of 'Shoplifting.

Plagiarism. Stealing a sister's boyfriend. Wrecking a boyfriend's car. Daddy issues. Mommy issues'. 'Uh-huh. OK' is his sole response to these apparently tedious (teen) issues, minimising their importance through recourse to generic categorisation (Patterson 2010).

While ABC Family, the critical reception and the fan community do not openly suggest the television show to belong to a 'mystery' genre, their deliberation in speaking about that mystery remains hugely suggestive. ABC Family intends Pretty Little Liars to link directly with their network description (as the show does deal with interpersonal relationships, diversity, heart, passion and humour), but it does not preclude the show to be solely a 'drama'. Mystery can just as easily unearth and debate controversial (teen) issues, or else the show must eliminate those direct links to coming out, weight, image, etc... Whether intended or not, 'drama' becomes secondary to the mystery, especially as viewers come to grips with Emily Fields and her heart clenching, and at times poignant, coming out story.

In conclusion, I have evaluated the ways in which genre carries cultural power and how the reliance upon one genre delimits or may delimit the cultural power or cultural relevance of another. The distinctions made between genres have moved beyond personal preference and taste in television generic categorisations in lieu of cultural commentary on and intervention in relevant, contemporary (teen) issues. Whilst I have not suggested that mystery is more important than 'drama' - in fact it may always be a part of 'drama' - I do suggest that mystery should not be elided by 'drama' as it works cogently to commentate on and to intervene in issues of (teen) sexuality, among others. Furthermore, I have suggested that mystery has been excluded almost altogether in current television scholarship, a mystery itself as it has historically been an important genre in literature, theatre and film. Consequently, mystery, much like the history of transgressive or adverse sexualities and sexual identifications, has become an overlooked, forgotten or, rather, ignored genre in television scholarship. This lack in scholarship on mystery television is revealing in that it perpetuates how the industry and the critics interpret and understand mystery, and thus lend a particular viewpoint to their audiences.

Through my examination of Emily's coming out narrative I have illustrated the ways in which mystery affects the 'drama,' and not conversely. On the one hand, this article has demonstrated genre's fluidity, but also, most importantly, that 'power relations' are central to our understanding of genre. Perhaps these power relations can themselves be renegotiated, much like Emily's

\footnotetext{
${ }^{6}$ Interestingly, there is an evident link between mystery and soap opera within the context of Pretty Little Liars and Desperate Housewives (ABC, 2004-12), but even more notable is this link that has been fashioned between telenovelas in Latin American programming and mystery (see, for example, IMDB's 'Best “Soap Opera” Mystery Television' (Anon. 2014b).
} 
sexuality narrative renegotiated the heterosexual narrative assumed by the audience. Moreover, I have highlighted here the relevant academic and critical reception and industry documents that would reiterate a proclivity by these authoritative influences for privileging particular genres. ABC Family's statement of purpose provides an enlightening framework within which shows are developed and brought to fruition as based on implicit, genre-defined discursive hierarchies. Further, their decision to generically categorise a show within their press releases creates a preconception by the reviewing critics, who then arguably influence the audience's generic expectations. Thus, the interrogation of these industry practices to define or categorise television programming against academic attentions (or how academics focus on one area and neglect others) mirrors how society focuses on the predominance of one sexuality over another. Identifying and understanding how a genre works in tandem with other genres ultimately demonstrates innate power structures within genre classification practices; and thus, the stronghold of dominant sexual identities over others.

\section{References}

Anonymous (2010) 'Breaking News - Never Trust a Pretty Girl with an Ugly Secret, in the New ABC Family Original Series "Pretty Little Liars", TheFutonCritic.com, [online], 6 May. Accessible at http://www.thefutoncritic.com/news/2010/05/06/never-trust-a-pretty-girl-with-anugly-secret-in-the-new-abc-family-original-series-pretty-little-liars-35609/20100506abcfamily01/. Accessed 15 April 2012

--- (2012) ‘ABC Family Description', ABC Family Medianet, [online]. Accessible at http://www.abcfamilymedianet.com/abcfamily/description.shtml. Accessed 15 April 2012

--- (2014a) 'Most Popular Mystery TV Series', Internet Movie Database, [online]. Accessible at http://www.imdb.com/search/title?at=0\&genres $=$ mystery\&sort=moviemeter,asc\&title_type=tv_seri es. Accessed 7 January 2014

--- (2014b) 'Best “Soap Opera” Mystery Television', Internet Movie Database, [online]. Accessible at http://www.imdb.com/keyword/soap-opera/?title type=tv\&genre=mystery. Accessed 6 January 2014

Allen, D. W. (1995) 'Homosexuality and Narrative', Modern Fiction Studies, 41(3-4), 609-634

Becker, R. (2006) Gay TV and Straight America, New Jersey: Rutgers University Press

Bourdieu, P. (1984) Distinction: A Social Critique of the Judgement of Taste, R. Nice (trans.), Massachusetts: Harvard University Press

Callister, M., Coyne, S. M., Stern, L. A., Stockdale, L., Miller, M. J. and Wells, B. M. (2012) 'A Content Analysis of the Prevalence and Portrayal of Sexual Activity in Adolescent Literature', Journal of Sex Research, 49(5), 477-486

Carson, B., and Llewellyn-Jones, M. (2000) 'Introduction: Issues of Cultural Identity', in B. Carson and M. Llewellyn-Jones (eds), Frames and Fictions on Television: The Politics of Identity within Drama, Exeter: Intellect books, 2000, pp.1-16

Casey, B., Casey, N., French, L. and Lewis, J. (2008) Television Studies: The Key Concepts, $2^{\text {nd }}$ ed., Oxon: Routledge

Cawelti, J. G. (2004) Mystery, Violence, and Popular Culture, Wisconsin: Wisconsin Press 
Creeber, G., Miller, T and Tulloch, J. (2001) The Television Genres Book, London: BFI

Davis, G., and Dickinson, K. (2004) Teen TV: Genre, Consumption and Identity, London: BFI

Davis, G. and Needham, G. (eds), (2009) Queer TV: Theories, Histories, Politics, Oxford: Routledge

Dhaenens, F. (2013) 'Teenage Queerness: Negotiating Heteronormativity in the Representation of Gay Teenagers in Glee', Journal of Youth Studies, 16(3), 304-317

Ernst, A. (2010) “"Pretty Little Liars”'TM On Your TV This June', Crushable, B5media Lifestyle Network, [online], 15 April. Accessible at: http://crushable.com/entertainment/pretty-little-liars-onyour-tv-this-june. Accessed 10 April 2012

Farrier, S. (2000) 'Ga(y)zing at Soap: Representation and Reading - Queering Soap Opera', in B. Carson and M. Llewellyn-Jones (eds), Frames and Fictions on Television: The Politics of Identity within Drama, Exeter: Intellect books, pp. 86-99

Gamson, J. (2005) 'The Intersection of Gay Street and Straight Street: Shopping, Social Class, and the New Gay Visibility', Social Thought and Research, 26(1-2), 3-18

Glick, I. O. and Levy, S. J. (1962) Living with Television, New Brunswick: Transaction Publishers

Keveney, B. (2013) 'The True Sign of 'Liars' Success is in Social Media', USAToday.com, [online], 10 June. Accessible at http://www.usatoday.com/story/life/tv/2013/06/10/pretty-little-liarsabc-family-social-media/2399921. Accessed 6 January 2014

McCabe, J. and Akass, K. (eds) (2007) Quality TV: Contemporary American Television and Beyond, London: I. B. Tauris

Meyer, M. D. E., and Wood, M. M. (2013) 'Sexuality and Teen Television: Emerging Adults Respond to Representations of Queer Identity on Glee', Sexuality \& Culture, 17, 434-448

Mills, B. (2009) The Sitcom, Edinburgh: Edinburgh University Press

Mittell, J. (2001) 'A Cultural Approach to Television Genre Theory', Cinema Journal, 40(3), 3-24

--- (2004) Genre and Television: From Cop Shows to Cartoons in American Culture, London:

Routledge

--- (2012-13, pre-publication edition) Complex TV: The Poetics of Contemporary Television Storytelling, MediaCommons Press, Accessible at http://mcpress.mediacommons.org/complextelevision/. Accessed 31 December 2013

Patterson, T. (2010) 'A Lustrous and Irresistible Show Concerning Teenage Nonsense', Slate.com, [online] 1 July. Accessible at http://www.slate.com/articles/arts/television/2010/07/pretty_little_liars.html. Accessed 20 April 2012

Ross, S. M., and Stein, L. E. (2008) Teen Television: Essays on Programming and Fandom, North Carolina: McFarland

\section{Filmography}

Dawson's Creek (1998-2003), created by Kevin Williamson, USA: The WB (Outerbank Entertainment/Columbia TriStar Television/Granville Productions/Sony Pictures Television) 
Desperate Housewives (2004-12), created by Marc Cherry, USA: ABC (Cherry Productions/Touchstone Television/ABC Studios)

Downton Abbey (2010- ), created by Julian Fellowes UK: ITV (Carnival Films/Masterpiece)

Greek (2007-11), created by Patrick Sean Smith, USA: ABC Family (Piller Squared/The Segan Company)

Lost (2004-10), created by J. J. Abrams, Damon Lindelolf and Jeffrey Lieber, USA: ABC (Bad Robot Productions/Touchstone Television/ABC Studios)

Mad Men (2007- ), created by Matthew Weiner, USA: AMC (Weiner Bros/Silvercup Studios/Lionsgate Television/AMC Studios)

Melrose Place (1992-9), created by Darren Star, USA: FOX (Darren Star Productions/Spelling Television)

Murder, She Wrote (1984-96), created by Peter S. Fischer, Richard Levinson and William Link, USA: CBS (Corymore Productions/Universal TV)

Pretty Little Liars (2010- ), created y: I. Marlene King and Sara Shepard, USA: ABC Family (Alloy Entertainment/Warner Horizon Television)

Skins (2007- ), created by Bryan Elsely and Jamie Brittain, UK: E4 (Company Pictures/Stormdog Films)

The O.C. (2003-7), created by Josh Schwartz, USA: FOX (Warner Bros Television/College Hill Pictures Inc.)

Veronica Mars (2004-7), created by Rob Thomas, USA: UPN (Silver Pictures Television/Stu Segall Productions/Rob Thomas Productions)

The West Wing (1999-2006), created by Aaron Sorkin, USA: NBC (John Wells Productions/Warner Bros) 